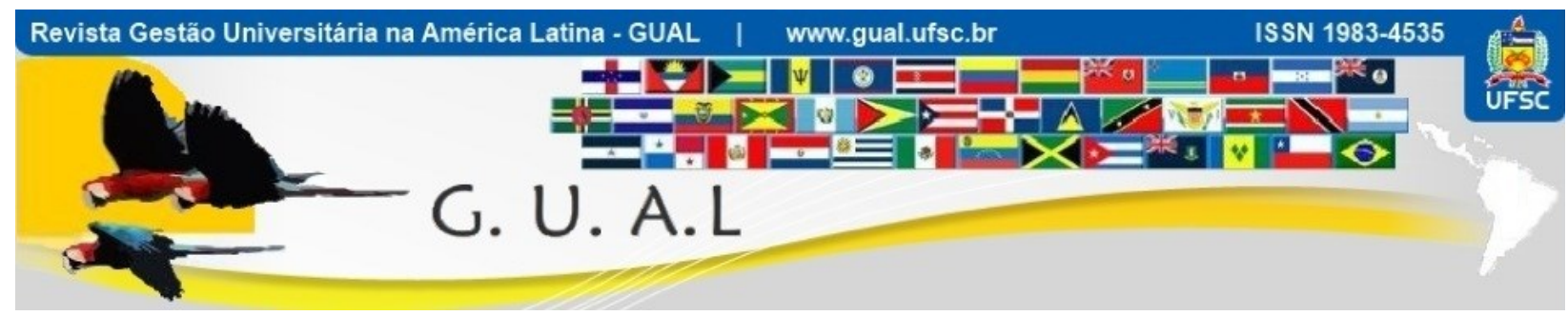

DOI: http://dx.doi.org/10.5007/1983-4535.2015v8n1p177

\title{
UMA ANÁLISE DOS MODOS DE REGULAÇÃO NOS AMBIENTES VIRTUAIS DE ENSINO
}

\section{NOTES ON THE MODES OF REGULATION IN VIRTUAL ENVIRONMENTS FOR EDUCATION}

Nei Antonio Nunes, Doutor

Universidade do Sul de Santa Catarina - UNISUL neinunes@,bol.com.br

André Luis da Silva Leite, Doutor Universidade Federal de Santa Catarina - UFSC andre.leite@ufsc.br

Recebido em 28/janeiro/2014

Aprovado em 27/outubro/2014

Sistema de Avaliação: Double Blind Review

Esta obra está sob uma Licença Creative Commons Atribuição-Uso. 


\title{
RESUMO
}

Neste artigo, discute-se alguns aspectos que envolvem a presença das novas tecnologias na educação, com foco nos modos de regulação nos ambientes virtuais de ensino. Parte-se da premissa de que o atual desenvolvimento e a disseminação da educação virtual não garantem qualquer valor intrínseco que a exima de ser inquirida e, assim, inserida num debate amplo que vise a refletir sobre os impactos da inserção das novas tecnologias na sociedade brasileira. Tomando por referências as análises de Michel Foucault sobre a regulação ambiental promovida pelos dispositivos de segurança, discute-se as novas tecnologias de controle com incidência sobre as "multiplicidades" nos diferentes "meios", como os espaços virtuais de ensino. Nesta reflexão, reafirma-se o caráter fundamental da crítica sobre os distintos modos de regulação (virtual ou não) e de suas produtividades. Trata-se de uma discussão teórica (pesquisa bibliográfica) na qual figuram conceitos extraídos de pesquisadores da educação, bem como da produção genealógica de Foucault.

Palavras-chave: Tecnologias. Ambientes Virtuais. Educação. Regulação. Crítica.

\begin{abstract}
In this paper, we discuss some aspects that involve the presence of new technologies in education, with a focus on regulation modes in distance learning environments. We start from the idea that the current development and spread of virtual education do not guarantee any intrinsic value that exempts to be surveyed and thus entered into a broad debate aimed at reflecting on the impact of the inclusion of new technologies in the Brazilian society. According to Michel Foucault's analyses references on environmental regulation promoted by security devices we discussed new technologies of control with focus on the "Multiplicities" in different "media" such as virtual spaces. In this reflection, we reaffirm the fundamental nature of the criticism about the different modes (virtual or not) and their productivity. We did a theoretical discussion (literature search) which included concepts drawn from educational researchers as well as Foucault's genealogical production.
\end{abstract}

Keywords: Technologies. Virtual Environments. Education. Regulation. Criticism. 


\section{INTRODUÇÃO: O ADVENTO DAS NOVAS TECNOLOGIAS E SEU IMPACTO NA EDUCAÇÃO FORMAL}

A presença das novas tecnologias em nos dias atuais tem influenciado profundamente a vida dos indivíduos e dos grupos sociais. Principalmente nas últimas décadas do século XX e neste limiar do século XXI, os resultados tecnológicos além de contribuírem decisivamente para a satisfação de muitas das necessidades humanas, marcam de forma indelével os padrões de comportamento e os valores das pessoas em escala mundial. Prova disso é a crescente importância atribuída à inserção das Tecnologias de Informação e Comunicação (TIC) no cotidiano de nossas sociedades, sobretudo nas últimas décadas. Por exemplo, TVs (“abertas" e "fechadas"), Vídeos Cassetes, DVDs, Telefones Celulares, Computadores - e mais recentemente, iPods, IPhones, Tablets...- ampliaram as possibilidades de comunicação e de acesso as informações, diversificando os modos de interação entre as pessoas tornando-os rápidos e informais. Aliás, o advento da Internet é um ponto de inflexão nestas novas tecnologias, pois leva ao paroxismo nos ambientes virtuais a ação humana de comunicar e informar.

Tais tecnologias têm influenciado a Educação Formal de várias maneiras. O acesso por parte das escolas aos aparelhos acima citados - e a tantos outros - deu aos professores múltiplas possibilidades para o enriquecimento de suas aulas. Cabe salientar que o uso da Internet viabilizou novas potencialidades no ensino e na pesquisa, disponibilizando aos corpos docentes e discentes um variegado campo de interlocução e de estudo, para além dos limites espaciais das instituições.

Nos últimos anos, o aparecimento de diversos cursos de educação a distância (EaD) viabilizados pela criação dos Espaços Virtuais de Aprendizagem (EVA) e em consonância com as diretrizes do Estado Brasileiro para a Educação (Decreto da Presidência da República, número 5.622, de 19 de dezembro de 2005, que normatiza o Ensino a Distância no País), tem gerado a expectativa de que a educação formal brasileira possibilite maior inclusão social sem abrir mão da excelência acadêmica. Este ideal impõe, por exemplo, mudanças significativas na estrutura educacional. De um lado, temos com o desenvolvimento das TIC a necessidade de investimentos financeiros expressivos no intuito de promover alterações e o aparelhamento nos ambientes de ensino (tanto de cursos presenciais quanto a distância), de outro, a urgência de mudanças nas metodologias de ensino e pesquisa. Ademais, a literatura sobre o tema tem mostrado que a existência de material didático apropriado - com profundidade reflexiva e rigor conceitual, comunicados com linguagem didática e dialógica -, de biblioteca virtual com 
acervo qualificado e diversificado, de professores e de alunos preparados para o uso das novas tecnologias, é condição sine qua non para o êxito do ensino a distância.

Todavia, nunca é demais lembrar que o atual desenvolvimento e disseminação da educação virtual não the garantem qualquer valor intrínseco - ou status de verdade e/ou bondade essencial - que a exima de ser inquirida e, assim, inserida num debate mais amplo e profundo que vise refletir sobre os dilemas que envolvem a inserção das novas tecnologias na sociedade brasileira.

Neste artigo, procuramos trazer a tona alguns aspectos dos intrincados jogos de forças próprios às relações entre os saberes pedagógicos e as práticas educacionais, nos quais as tecnologias virtuais são peças-chave. Procurando inventariar alguns dos seus dilemas, ao refletirmos sobre domínios da experiência dos sujeitos na educação, discutimos a emergência de modos de regulação nos ambientes virtuais de ensino. Trata-se, pois, de uma discussão pertinente a análise dos atuais processos de subjetivação que envolvem o trabalho docente e a constituição da autonomia dos discentes (esta última, um dos princípios basilares da EaD). Para tanto, utilizamos as reflexões de Michel Foucault (1926-1984), contidas, sobretudo, no curso "Segurança, território, população" (1978), sobre as tecnologias de regulação ambiental. Sob o ponto de vista metodológico, enfatiza-se que este artigo resulta numa discussão teórica (pesquisa bibliográfica) na qual figuram conceitos extraídos de pesquisadores da educação, bem como da produção genealógica de Foucault da segunda metade da década de 1970. Quanto ao "método foucaultiano" de investigação, constitutivo dos estudos genealógicos dos anos de 1970, e a sua aplicação no escrutínio dos espaços de ensino, Veiga-Neto salienta que: "Foi Foucault aquele que melhor nos mostrou como as práticas e os saberes vêm funcionando, nos últimos quatro séculos, para fabricar a Modernidade e o assim chamado sujeito moderno. Foi com base em Foucault que se pôde compreender a escola como uma eficiente dobradiça capaz de articular os poderes que aí circulam com os saberes que a enformam e aí se ensinam, sejam eles pedagógicos ou não.” E conclui: "não existe método foucaultiano, a menos que se tome a palavra "método" num sentido bem mais livre do que os sentidos que lhe deu o pensamento moderno, principalmente a partir de Ramus e Descartes." Assim sendo, o procedimento foucaultiano de investigação deve ser entendido, sobretudo, "como 'uma certa forma de interrogação e um conjunto de estratégias analíticas de descrição"” (VEIGA-NETO, 2005, p. 17-20). 
$\mathrm{Na}$ trama argumentativa aqui proposta, discute-se importantes dilemas dos processos atuais de regulação vivenciados em ambientes educacionais, a exemplo dos espaços virtuais de ensino.

\section{O ENSINO EM AMBIENTES VIRTUAIS: MUDANÇAS DIDÁTICO- PEDAGÓGICAS E O USO DAS NOVAS TECNOLOGIAS}

Há uma gama considerável de pesquisadores brasileiros que tem se dedicado ao estudo da atuação docente nos ambientes virtuais. Expressões como "novo professor", "professor do futuro" e "professor coletivo" têm mostrado, por exemplo, como muitos destes teóricos - isso para não mencionarmos os governantes brasileiros - depositam confiança e atribuem responsabilidades aos docentes dos cursos virtuais. As inovações na docência, em ambientes virtuais, dar-se-iam na articulação entre as dimensões pedagógica, didática e tecnológica (BELLONI, 2009a). Como sugere Almeida, a esfera didática relaciona-se às competências do docente em sua área de conhecimento. O âmbito pedagógico refere-se à mediação, comunicação, orientação e acompanhamento dos discentes e, desta forma, aos processos de aprendizagem. Já o domínio das tecnologias, dá condições para que o docente opere e explore os recursos por ele fornecidos (ALMEIDA, 2005).

Diversos autores sugerem que diferente do professor tradicional que, em regra geral, é tido como centro do conhecimento e das atenções em sala de aula, o docente on-line é um mediador e, por isso, peça-chave nas transformações operadas no ato de ensinar/aprender no meio virtual. Explicando melhor, o professor virtual não é o centro do saber mas um mediador que, com o domínio da tecnologia, desenvolve atividades interagindo com os discentes, com a equipe técnica e com a instituição de maneira distinta do que tradicionalmente tem ocorrido no ensino presencial (BORBA, 2008). Desta forma, no EaD ele é chamado assumir múltiplas funções. Em certo sentido, o professor deixa de ser considerado um ente individual passando a ser entendido como uma entidade coletiva - em certa medida ele é tido como uma "instituição".

Quanto a sua relação com o aluno, pelo fato de abdicar da posição central no que tange ao conhecimento e ao poder, ele atuará como promotor de um novo tipo de estudante, agora autônomo, bastante próximo a figura do usuário/cliente (BELLONI, 2009a). A imagem do professor-online é tida como garantia da boa mediação entre os meios tecnológicos e os anseios dos alunos. Seu papel como produtor de mensagens escritas, o uso producente que faz das ferramentas da máquina, dos programas, mas também os saberes que partilha, seriam 
reveladores da boa adequação entre os meios tecnológicos e os fins do ensino (BELLONI, 2009b).

A harmonia entre fins e meios facilitaria o trabalho autônomo dos discentes. Junto à descentralização do professor virtual, existiria uma série de medidas garantidoras da autonomia no estudo. Por exemplo, o conteúdo mínimo de cada disciplina seria disponibilizado por meio de livros didáticos, bem como pela indicação de extensa bibliografia suplementar sobre os temas abordados. Além disso, a forma de avaliação permitiria ao aluno/grupo exercitar a construção da autonomia (por meio de cooperação) ao ter que elaborar projetos de disciplina. Também caberia ao discente, além da opção do conteúdo, a escolha da forma mais adequada de abordá-lo. No limite, estas escolhas seriam reveladoras da construção da autonomia do sujeito do conhecimento no processo educativo virtual (DIAS; LEITE, 2010).

Embora possa ser questionada a fração de otimismo presente em muitas destas convicções, é possível afirmar que as atuais relações entre as tecnologias e as práticas didático-pedagógicas nos ambientes virtuais apresentam diferenças - singularidades, especificidades - se comparadas às tecnologias disciplinares da educação presencial. Para situar estas últimas, basta lembrar as análises de Vigiar e punir sobre o poder disciplinar que incide sobre os corpos dos sujeitos, por meio de uma anátomo-política, nas instituições modernas de ensino (FOUCAULT, 1993). Contudo, lá e cá (tanto nos espaços disciplinares quanto nos ambientes virtuais), os conhecimentos tecnológicos são permeados por práticas diversas, valores sociais distintos e discursos variados.

Nesse sentido, Castro, explicando o léxico foucaultiano, sugere que as tecnologias são práticas, táticas e estratégias que se definem pela regularidade e a racionalidade que acompanham os modos de fazer. Assim, em Foucault, haveria diferentes tipos de tecnologia: tecnologias do corpo, do sexo, da política, de si mesmo e da verdade - definição que caberia também (cremos) às Tecnologias de Informação e Comunicação. Desse modo: "Os termos 'técnica' e 'tecnologia' agregam à ideia de prática aos conceitos de estratégia e tática." (CASTRO, 2009, p. 412-413.) O que faz com que, em graus distintos de inserção e com efeitos diversos, as tecnologias (encontradas em diferentes domínios da experiência cognitiva, política e social) possam ser definidas como instrumentos das relações de poder nas quais os sujeitos procuram, em maior ou menor intensidade e regularidade, conduzir as condutas uns dos outros. O que queremos salientar, nesse momento, é que as tecnologias - entendidas como práticas - presentes nos distintos ambientes e modos de educação, não anulam (pelo 
contrário, intensificam, sofisticam,...) a existência de relações de poder. E mais, elas funcionam como catalisadores produtivos. Para aprofundarmos a discussão, veremos, a seguir, como Foucault define as novas tecnologias de regulação que emergem a partir da modernidade nos dispositivos de segurança.

\section{DISPOSITIVOS DE SEGURANÇA E A REGULAÇÃO AMBIENTAL}

Foucault (2008a), em "Segurança, território, população", que os dispositivos modernos de segurança estruturam-se, na segunda metade do século XVIII e no início do século XIX, com base em problemas como o da "circulação". Em torno de questões dessa ordem são pensadas muitas das soluções político-sociais e econômicas da época. Neste trabalho, destaca-se que o dispositivo de segurança estrutura-se com base no(a): a) problema da circulação, b) tratamento do aleatório, c) especificidade da normalização da segurança, d) correlação entre as técnicas de segurança e a população.Visando delinear o tratamento dado pelo dispositivo de segurança à questão da circulação nos espaços urbanos (ar, pessoas, mercadorias,...), buscou-se aperfeiçoar a cidade como um agente de circulação. Em termos práticos, para que isso acontecesse seria preciso desfazer as aglomerações desordenadas, viabilizar espaço às novas funções econômicas e administrativas, regulamentar as relações da cidade com as proximidades rurais, como também prognosticar o crescimento do perímetro urbano. Urge a necessidade de abrir (ou ampliar) eixos que atravessassem a cidade e suas ruas visando garantir as seguintes funções: higiene e arejamento; comércio interior na cidade; articulação da rede de ruas internas com estradas externas viabilizando a circulação de mercadorias, mas sem abrir mão do controle aduaneiro; efetivação da vigilância como resposta ao problema da insegurança nas cidades.

$\mathrm{Na}$ intenção de tornar isso possível, o dispositivo de segurança procurou sustentar-se num certo número de dados materiais. Assim sendo, buscou agir sobre "algo" já dado, como: a disposição de diversos espaços, o escoamento das águas, as ilhas, o ar etc. Nesse ponto, chamamos a atenção para o seguinte aspecto: não se trata, com a ação da segurança, de procurar alcançar um ponto (ótimo) de perfeição, tal qual almeja o poder disciplinar. Seu objetivo é, pois, fazer com que a circulação aconteça da melhor forma possível, mas sem a pretensão da anulação absoluta das inconveniências. Trata-se, então, de tentar reduzir os "danos" que atingem e que são gerados nos espaços, sem, contudo, a expectativa de suprimilos definitivamente. Dessa forma, o dano pode ser reduzido, parcialmente controlado, mas também racionalmente tolerado. 
O tratamento dado pelo dispositivo de segurança ao dano (leia-se: doenças, contravenções, má-educação, analfabetismo, penúria,...) pressupõe o uso de instrumentos como os dados quantitativos, a estatística. Cabe acrescentar que os elementos constitutivos da estrutura dos planejamentos dos espaços - delineados nos projetos arquitetônicos - encontram justificação na sua "polifuncionalidade" (por exemplo: a rua como campo de proliferação de doenças, ambiente de contravenções e violências, espaço também por meio do qual se levam as mercadorias etc.). Por esse motivo, transformam-se em alvos de "governo" (regulação das condutas por parte, por exemplo, do Estado) e devem ser geridos por dispositivos de segurança. E mais, o cálculo da segurança (presente nos projetos arquitetônicos, nas medidas administrativas, na organização de diferentes perímetros) vai operar levando em consideração o futuro, procurando projetar (estatisticamente) o que pode acontecer. A segurança visa, então, à gestão de um campo de acontecimentos que só pode ser gerido por meio de estimativas de probabilidade.

O espaço do qual a segurança se ocupa é constituído por variações diversas de acontecimentos que, por sua vez, remetem às experiências temporais e aleatórias. Estas, conforme a segurança, devem ocupar um lugar determinado: o espaço em que os elementos aleatórios se manifestam e se desenvolvem é o meio. O que é o meio? Explica Foucault que a problematização da circulação remete, invariavelmente, à noção de meio. Isso porque o meio (como conjunto de dados naturais e artificiais: rios, pântanos, morros, aglomeração de indivíduos, escolas, casas...) é o suporte e o elemento de circulação de uma ação, ou seja, ele é o espaço no qual a circulação acontece. É também um efeito de massa que age sobre todos aqueles que nele estão. Existe, no meio, um encadeamento circular dos efeitos e das causas. Além disso, ele é um campo de intervenção que não tem por meta atingir os indivíduos enquanto um conjunto de sujeitos de direito, mas como elementos da população (FOUCAULT, 2008a). Em síntese, o mecanismo de segurança age sobre o meio fazendo com que as diferentes singularidades (pessoas, acontecimentos, coisas,...) nele se relacionem e interajam.

Grosso modo, podemos dizer que no modelo da soberania estatal a lei aparece como a instância que pode proibir (“concepção jurídica do poder”). As práticas disciplinares, por sua vez, visam prescrever o que os indivíduos (seus corpos) devem ou não devem fazer ("poder disciplinar"). Já o dispositivo de segurança, sem proibir nem prescrever, mas dando-se evidentemente alguns instrumentos de proibição e de prescrição, objetiva "responder a uma realidade de maneira que essa resposta anule essa realidade a que ela responde - anule, ou 
limite, ou freie, ou regule." Com o argumento positivo de evitar/corrigir o dano impedindo, com isso, os efeitos mais nocivos que põem a população em perigo, a regulação acontece no próprio elemento da realidade - autorregulação no interior de um ambiente (FOUCAULT, 2008a, p. 27-28).

Com o que se coloca até aqui, é possível entrever que não há, na modernidade, rejeição das técnicas de segurança tanto por parte dos Estados absolutistas quanto das gestões governamentais liberais (desde os primeiros movimentos da fisiocracia). E mais, no paradigma da segurança não aparece a indicação de incompatibilidade entre a defesa da liberdade econômica e o exercício das práticas da segurança. Cabe salientar que nesta discussão dos dispositivos modernos de segurança, a liberdade (liberal) é por Foucault definida, sobretudo, como a "liberdade de circulação". Assim sendo, caberia ao dispositivo de segurança viabilizar as condições de regulação (e autorregulação ambiental: regulação presente no próprio elemento da realidade) que fazem com que os indivíduos possam circular ("livremente") no meio econômico e no meio social: de um lado, o fomento da liberdade, de outro, a regulação de importantes movimentos do conjunto social (FOUCAULT, 2008a).

Além disso, o dispositivo de segurança procura estabelecer um processo homeostático pelo qual as manifestações dos membros da população e a regulação do meio se complementam e locupletam. Conforme sabemos, a noção de homeostase é utilizada por diferentes áreas do saber como a biologia, a ecologia e a sociologia. Grosso modo, o termo indica "manter as coisas semelhantes ao que são ou como são." Para os funcionalistas, a homeostase compõe o argumento de que as sociedades se organizam de modo que tendem para formas relativamente estáveis. Essas formas podem ser baseadas no consenso geral sobre valores e coisas. Contudo, há contestações sobre essas convicções. Argumenta-se, por exemplo, que o nível de consenso e estabilidade sustentado pelos funcionalistas seja inexistente (JOHNSON, 1997, p. 125).

Em vez de simplesmente inibir as múltiplas manifestações do que é considerado como a "aleatoriedade" (cabe ilustrar: comportamentos disformes, inconveniências que ferem a tradição e os costumes sociais, etc.), deixa-se que apareçam, pois o seu controle (autocontrole) pressupõe que essas antes se revelem. Assim sendo, no nível de intervenção homeostático objetiva-se, por exemplo, controlar os "danos aleatórios", sem, contudo, suprimi-los (SENELLART, 2008a).

Tomando estas análises como base, podemos afirmar que os padrões racionais de equilíbrio (que são, em tese, a antítese dos disparates dos danos) comportam um nível de 
descarte estatisticamente definido. A garantia da melhor vida do todo social - sua segurança não exclui as desventuras dos casos isolados, das exceções, daqueles que compõem o "desvio padrão" - por exemplo: alunos tidos como contraventores, anormais, negligentes, improdutivos, repetentes. Acrescente-se a isto que: deixar que se manifestem as diferenças dos "sujeitos-estudantes" e dos acontecimentos (suas contingências) no "meio" é também viabilizar sua identificação (estatística) e regulação (ou autorregulação) e, em situações determinadas, o seu descarte.

Mas como é possível, de acordo com o paradigma da segurança, conter o que é considerado como "perigo", como ameaça as individualidades e as coletividades? De modo geral, trata-se, no dispositivo de segurança, de fazer com que os vários elementos possam agir uns em relação aos outros (anulação progressiva dos fenômenos pelos próprios fenômenos), e não como efeito da obediência cega a uma instância superior - rei, presidente, ministro, magistrado, chefe, diretor, professor, etc. Junto disso, a segurança deve fazer com que a ação dos que governam/lideram a população seja invariavelmente tida como necessária e suficiente ante as supostas ameaças de perigo - governar as populações visando conter o que é apregoado como perigo. Atente-se que "trata-se, de certo modo, de delimitá-los em marcos aceitáveis, em vez de impor-lhes uma lei que lhes diga não. Não é portanto no eixo soberanosúditos, tampouco é na forma da proibição que os mecanismos de segurança põem-se a funcionar." (FOUCAULT, 2008a, p. 86).

Diga-se a propósito, o epicentro da condução das condutas na modernidade (do seu governo) é a gestão dos conjuntos populacionais. No liberalismo, a população é considerada a finalidade, o instrumento e o objeto do ato de governar. Com isso queremos indicar que as políticas econômicas, a liberdade de mercado, as instituições educacionais passam a ser problematizadas como esferas de investimento de um poder que visa gerir integralmente a vida humana. Para tanto, são utilizados os aparelhos de segurança. Embora correspondam a positividades distintas, tanto no liberalismo quanto no Estado de polícia estes aparelhos devem promover uma efetiva "assepsia social". Na governamentalidade liberal, essa ação visa evitar os efeitos mais nocivos dos "danos", como também o mal-estar geral provocado pela constante sensação de perigo. É esse o novo campo de ação da biopolítica, ou seja, a gestão, a regulação, o controle dos corpos coletivos. No que tange ao aparecimento da temática da biopolítica em "Segurança, território, população", dirá Gadelha que: "A novidade desse curso, todavia, é a de proceder a uma nova leitura da biopolítica, tomando como fio condutor a noção de governo, isto é, tipos de racionalidade que envolvem conjuntos de procedimentos, 
mecanismos, táticas, saberes, técnicas e instrumentos destinados a dirigir a conduta dos homens." (GADELHA, 2009, p. 120).

Com a emergência dos dispositivos de segurança há a expansão das formas de regulação dos conjuntos populacionais. Assim, o fomento do perigo e a relativa "assepsia do dano aleatório" nos espaços de circulação fazem parte das novas estratégias de gestão da vida humana com incidência sobre o "meio ambiente" (e não diretamente sobre a singularidade dos corpos). Ou seja, ao gerir os perigos o poder biopolítico centra as suas ações na gestão de corpos coletivos. Os indivíduos só interessam ao dispositivo de segurança na medida em que eles, como singularidades, participam de efeitos de conjunto que podem reverberar (estatisticamente) na coletividade. Podemos dizer, assim, que as práticas modernas de segurança priorizam o tratamento da coletividade tida como "múltiplo enquanto múltiplo". Nesse sentido, o controle parcial dos danos corresponde a uma orientação estatística de tipo ambiental (geral), e não tanto a uma objetivação disciplinar (do corpo singular).

Nessa modalidade biopolítica, a promessa (liberal) de segurança ante os perigos e a defesa incondicional da liberdade de mercado, caminham lado a lado com a regulação sobre o meio. A liberdade de circulação é conformada à determinação estatística dos níveis de perigo e, assim, à regulação empreendida pela segurança. A probabilidade evoca o padrão definidor tanto da normalidade, quanto do que é tido como equilíbrio social e descarte individual. Aliás, as perdas individuais, a supressão de algumas vidas, a baixa escolaridade de parte da população, o sucateamento de diversas instituições de ensino etc., são admitidas pelo padrão estatístico, pelo processo homeostático, na medida em que são consideradas, por exemplo, como casos isolados, como desvio padrão. Afinal, o que interessa a biopolítica são, sobretudo, os padrões de gestão e regulação no nível populacional.

Cabe dizer ainda que estas práticas de governo (gestão) dos outros, próprias da tecnologia de segurança, não se constituíram, historicamente, como espaços de problematização crítica e de vivência ampla da liberdade (positiva) e da autonomia humanas. Não há como ignorar que a absorção dos dispositivos de segurança por parte da arte liberal de governo sinaliza para a conformação entre a liberdade liberal e a gestão (regulação, controle) biopolítica da vida humana. Embora essas práticas de poder não prescindam de espaços concretos para sua efetivação, constituem-se em sofisticadas tecnologias de regulação em ambientes diversos, gerindo nos "meios" uma miscelânea de coletividades.

Levando em consideração estas análises foucaultianas sobre a tecnologia de regulação que emerge com os dispositivos de segurança, como também a convicção de que os diversos 
espaços de interação humana se constituem em ambientes de exercícios de poder, tecemos algumas considerações sobre a possibilidade da presença de modos de regulação nos ambientes virtuais de ensino. Comecemos, contudo, pela definição do termo multiplicidade e sua relação com a ideia de meio.

\section{4 À GUISA DE CONCLUIR: AS RELAÇÕES DE PODER NOS AMBIENTES VIRTUAIS DE ENSINO}

Como indicamos, no dispositivo de segurança a intervenção sobre as individualidades acontece, sobretudo, pela ação sobre a multiplicidade. Mas afinal, o que é o múltiplo? É o conjunto das singularidades, é o princípio de inteligibilidade resultante de um cálculo probabilístico. Nesse sentido, o múltiplo é definido na relação que ele tem com o meio ambiente. E o meio é - como mostramos -, em termos estatísticos, o espaço de viabilidade das diferentes "identidades singulares" (de indivíduos pertencentes, por exemplo, a grupos étnicos, religiosos, intelectuais, corporativos e/ou que expressam orientações sexuais, políticas, ideológicas diversas) e de sua circulação. As diferentes singularidades (pessoas e acontecimentos) se relacionam e interagem enquanto singularidades no meio. Como elemento do múltiplo, o conjunto das individualidades - leia-se: o conjunto dos sujeitos singularidades - é definido pela curva estatística, pela probabilidade da ocorrência, pelo desvio padrão. Desse modo, os modelos estatísticos fazem com que, em tantos momentos, as vidas singulares desapareçam enquanto individualidades, e só se manifestam no nível estatístico.

Entendemos que o conceito foucaultiano de multiplicidade é assaz importante no escrutínio das novas formas de vida (virtuais ou não) que compõem nossas sociedades atuais - e nelas os diferentes modos e espaços de ensino. Bem sabemos que, em nosso presente, urge como um imperativo o espectro da diferença. A defesa da pluralidade nas maneiras de ser e estar em sociedade, o respeito à diversidade em diversos campos e experiências humanas, têm provocado alterações tanto no ordenamento jurídico quanto nos valores sociais. Embora diferentes formas de preconceito persistam nas estruturas da sociedade brasileira, não há como negar que, sobretudo nas últimas décadas, o preceito da tolerância - próprio da ética liberal - vem ganhando, paulatinamente, importância nos discursos e nas instituições estatais e sociais. Embora não se tenha a pretensão de discutir o tema, cabe salientar a diferença entre o exercício da "tolerância" - imperativo das éticas liberais - e a luta ético-política por "reconhecimento", sustentada por diferentes movimentos sociais na atualidade Cabe salientar que, de acordo com os preceitos neoliberais, a prática da liberdade humana (como ação 
autônoma de sujeitos livres) não pode prescindir do fato de que os indivíduos vivam, o mais plenamente possível, o pluralismo - político, religioso, sexual, etc. (LAGASNEIRE, 2013) Contudo, é mister evitar o seguinte equívoco: achar que o alto valor social atribuído a pluralidade serve, por si só, como legitimação das tecnologias de poder que a viabilizam, bem como das produtividades que dela dimanam. Assim, tomando como pressuposto as inferências sobre a multiplicidade, mas restringindo o campo de análise ao tema tratado neste artigo, cabe questionar: quais consequencias são resultantes das tecnologias de mediação que agem como "facilitadoras" da pluralidade, da diversidade, no ensino virtual?

Se considerar o meio virtual como espaço de circulação multifuncional pelo qual a intervenção nas singularidades acontece pela ação sobre a multiplicidade, observa-se que as produtividades nos espaços virtuais e, assim, as funções do professor- mediador, são modos de intervenção, de práticas de poder e até de regulação dos alunos. A intervenção tecnológica em ambientes virtuais, na qual o professor tem papel importante, aconteceria não pelo controle individual - pela anatomo-política - tal qual acontece na tecnologia disciplinar, mas pelo controle da multiplicidade. Emerge, pois, nessas práticas, uma "normalização estatística". Por isso crê-se que, para o debate educacional, os modos de relação que se estabelecem entre o meio tecnológico e o múltiplo de alunos, e vice-versa, são tão significativos aos desafios ético-políticos que envolvem a autonomia humana quanto o fato de professores e alunos estarem em ambientes virtuais ou presenciais.

Como já indicado, o paradigma da segurança (presente em diversos modelos de gestão política, econômica, educacional...) objetiva estabelecer um processo homeostático no qual a liberdade (singular, individual...) e a autoregulação se complementam. Ou seja, ao invés de simplesmente inibir as diversas manifestações do dano aleatório - com ocorrência, por exemplo, nos ambientes virtuais de ensino -, deixa-se que apareça e só a partir disso procurase controlá-lo, mas não suprimi-lo. Por exemplo, os riscos e prejuízos individuais, a exclusão de estudantes numa determinada tarefa ou disciplina ou curso, o desnível educacional, a existência de analfabetos funcionais, seriam admitidos por este mecanismo homeostático. Isto porque a garantia da melhor vida do "todo" não exclui as desventuras dos casos isolados, das exceções - os riscos e prejuízos individuais são aceitos ante os supostos benefícios coletivos estatisticamente comprovados.

Talvez pareça exagerado falar de um padrão homeostático no ensino virtual, ou do estabelecimento de um padrão de normalização para o aluno virtual com base em critérios estatísticos - embora o ensino a distância também objetive (1) alcançar um equilíbrio na 
formação e (2) obter resultados que correspondam as expectativas tanto do Estado quanto de instituições privadas de ensino -; contudo, não é descabido dizer que na interação, cooperação e interatividade (nos em ambientes virtuais) também está presente a relação (bastante tensa) entre diferentes práticas que culminam na condução das condutas - manifestações da liberdade humana e também das formas de sujeição. Nunca é demais lembrar que deixar que se manifestem as diferenças dos indivíduos (suas contingências, o modo como circulam, etc.) é também viabilizar sua identificação e regulação (ou auto-regulação).

O ensino virtual não está isento das urgências de ordem econômica, das influências do Estado e das empresas privadas. Aliás, é possível questionar se os modelos do "estudanteusuário" e do "aluno-cliente" comportam, em sua riqueza e abrangência, os elementos que podem constituir a autonomia dos estudantes. Vale lembrar que o "indivíduo-empreendedor", bem próximo do cliente, mas não tão distante da ideia de usuário, constitui sua identidade a partir de um a priori que é o mercado competitivo. Nesse sentido, indica Foucault que na tecnologia de governo neoliberal o comportamento individual é regulado a partir da manipulação das variáveis econômicas. A manipulação do meio econômico (naturalização da verdade econômica, do mercado...) possibilita a intervenção no âmbito da multiplicidade, o que faz com que, a revelia da defesa da liberdade por parte dos liberais modernos e contemporâneos, os comportamentos singulares (em espaços virtuais ou não) possam ser probabilisticamente manipulados (FOUCAULT, 2008b). Em face do exposto, vale levantar questões como estas: se a intervenção sobre o meio limita a liberdade, que é condição para a autonomia, o que dizer da redução da autonomia do sujeito (professor ou aluno) a concepção de "sujeito-empreendedor competitivo"? Quais as consequencias ético-políticas deste reducionismo da subjetividade humana à lógica do mercado?

Conforme Foucault (2008b), os modos nos quais os sujeitos se inserem e participam dos “jogos" científicos, políticos e educacionais de "constituição da verdade" são decisivos no processo de formação de suas autonomias. Depreende-se disso que não há, quer seja no ensino presencial ou virtual, neutralidade ou não ingerência de uns sobre os outros - por exemplo, professor-aluno, alunos-professor, aluno-aluno. Ademais, as diversas demandas profissionais e mercadológicas sinalizam que, geralmente, na relação pedagógica os conteúdos e as avaliações, facilitados pelas novas tecnologias nos ambientes virtuais, procuram corresponder a interesses competitivos diversos. No que tange a interatividade nos vários âmbitos e ambientes, estamos sempre inseridos em relações de poder - também no campo educacional e, assim, nas práticas político-pedagógicas. Diga-se de passagem, o 
ambiente virtual também pode ser revelador, na rede (por exemplo: nos diversos momentos de interação e cooperação), não só das diferenças, mas também de profundas desigualdades entre as pessoas. Como lembram Foucault, existem formas de exclusão que só se efetivam por meio da inclusão dos indivíduos e das coletividades, facilitadas pela regulação ambiental: anulação progressiva dos fenômenos pelos próprios fenômenos (tidos estatisticamente como anormais, improdutivos, prejudiciais, perigosos).

Longe de desqualificar a modalidade de ensino virtual visa-se a reafirmar, aqui, a necessidade de empreender uma crítica permanente sobre o que o constitui como tal, inquirindo suas produtividades. À medida em que o meio virtual passa a ser considerado um fim em si mesmo, perde-se o olhar crítico sobre a tecnologia e os seus efeitos. Aliás, é bem possível que um dos grandes problemas a serem enfrentados pelos teóricos da educação não seja a existência de técnicas de regulação no ensino virtual, mas o fato destas, em tantos momentos, serem ignoradas. Até porque, para resistirmos aos excessos de governo precisamos identificar os novos modos de condução das condutas humanas e, assim, as tecnologias de regulação nos diversos ambientes. Cabe ilustrar: o olhar crítico sobre os atuais desafios da educação brasileira deve pôr em xeque a convicção de que o ensino virtual seja um fim em si mesmo e/ou a panacéia para todos os males da educação. Caminho diverso do otimismo exagerado é o da problematização constante do processo de ensino-aprendizagem dos cursos virtuais, das políticas (estatais ou não) a que estão vinculados, bem como das urgências econômicas e sociais a que correspondem em nossos dias. Na esfera da educação, esta atitude crítica - que não resulta de uma ação descompromissada com os rumos de nossa sociedade - pode ganhar a proporção de um éthos e, portanto, de uma prática refletida da subjetividade e, assim, de um exercício ético-político de liberdade. ${ }^{1}$

${ }^{1}$ É o que indica Larrosa quando, ao investigar a inserção das "Tecnologias do Eu" no universo educacional, questiona/exorta: "Ver-se de outro modo, dizer-se de outra maneira, julgar-se diferentemente, atuar sobre si mesmo de outra forma, não é outra forma de dizer "viver" ou "viver-se" de outro modo, "ser outro"? E não é uma luta indefinida e constante para sermos diferentes do que somos o que constitui o infinito trabalho da finitude humana e, nela, da crítica e da liberdade?" (LARROSA, 1994, p. 84).

\section{REFERÊNCIAS}

ALMEIDA, M.E.B. de. Desafios e possibilidades da atuação docente on-line. Revista PUCViva [on-line], São Paulo, n. 24, jul./set. 2005. Disponível em: http://www.apropucsp.org.br/revista/r24_r07.htm. Acesso em: 22 jan. 2012.

BELLONI, M.L. O que é mídia educação. Campinas: Autores Associados, 2009a (Coleção 
polêmicas do nosso tempo; 78).

BELLONI, M.L. Educação a distância. Campinas: Autores Associados, 2009b (Coleção educação contemporânea).

BERLIN, I. Dois conceitos de Liberdade. In: Berlin, I. Estudos sobre a humanidade. Uma antologia de ensaios. São Paulo: Companhia das Letras, 2002, p. 226-272.

BORBA, M. de C. et al. Educação a distância online. Belo Horizonte: Autêntica, 2008.

CASTRO, E. Vocabulário de Foucault. Um percurso pelos seus temas, conceitos e autores. Belo Horizonte: Autêntica, 2009.

DIAS, R.A.; LEITE, L.S. Educação a distância: da legislação ao pedagógico. Petrópolis: Vozes, 2010.

FOUCAULT, M. Vigiar e punir. História da violência nas prisões. Petrópolis: Vozes, 1993.

FOUCAULT, M. Segurança, território, população: curso dado no Collège de France (19771978). São Paulo: Martins Fontes, 2008a (Coleção Tópicos).

FOUCAULT, M. Nascimento da biopolítica: curso dado no collège de France (1978-1979). São Paulo: Martins Fontes, 2008b (Coleção Tópicos).

GADELHA, S. Biopolítica, governamentalidade e educação: introdução e conexões, a partir de Michel Foucault. Belo Horizonte: Autêntica Editora, 2009.

JOHNSON, A.G. Dicionário de Sociologia. Guia prático da linguagem sociológica. Rio de Janeiro: Jorge Zahar Editor, 1997.

LAGASNERIE, G. de. A última lição de Michel Foucault: sobre o neoliberalismo, a teoria e a política. São Paulo: Três Estrelas, 2013.

LARROSA, J. Tecnologias do eu e educação. In: SILVA, Tomaz Tadeu da. O sujeito da educação: estudos foucaultianos. Rio de Janeiro: Vozes, 1994, p. 35-86 (Ciências Sociais da Educação).

NOGUERA-RAMÍREZ, C. E. Pedagogia e governamentalidade ou da modernidade como uma sociedade educativa. Belo Horizonte: Autêntica Editora, 2011 (Coleção Estudos Foucaultianos).

SENELLART, M. Situação dos cursos. In: Foucault, M. Segurança, território, população: curso dado no Collège de France (1977-1978). São Paulo: Martins Fontes, 2008a, p. 495-538 (Coleção Tópicos).

VEIGA-NETO, A. Foucault \& a educação. Belo Horizonte: Autêntica Editora, 2005 (Pensadores \& Educação, 4). 